\title{
Role of MRI in Childhood Multiple Sclerosis
}

Hicham Jalal $^{1}$, Amine El Masloumi ${ }^{2 *}$, Anass Chehboun ${ }^{2}$, Meryem Ouali Idrissi ${ }^{1}$, Najat Cherif Idrissi El Ganouni ${ }^{1}$

${ }^{1}$ Professor, Departement of Radiology, Mother and Child's Hospital, Mohammed VIth Teaching Center, Medical school of Marrakesh, CadiAyad University, Marrakesh, Morocco

${ }^{2}$ Student, Departement of Radiology, Mother and Child's Hospital, Mohammed VIth Teaching Center, Cadi Ayad University, Marrakesh, Morocco

DOI: $10.36347 /$ sjmcr.2020.v08i02.042

| Received: 10.02.2020 | Accepted: 17.02.2020 | Published: 28.02.2020

*Corresponding author: Amine El Masloumi

Abstract

Case Report

Multiple sclerosis (MS) is characterized by inflammatory lesions of the white matter of the central nervous system, disseminated in time and space. The average onset age is 30 years. The infantile form is rare, The aim of this work is to report the clinical and radiological features of the childhood multiple sclerosis through a case report of a 13-year-old girl.

Keywords: Multiple sclerosis (MS), radiological features, inflammatory lesions, MRI.

Copyright @ 2020: This is an open-access article distributed under the terms of the Creative Commons Attribution license which permits unrestricted use, distribution, and reproduction in any medium for non-commercial use (NonCommercial, or CC-BY-NC) provided the original author and source are credited.

\section{INTRODUCTION}

Multiple sclerosis (MS) is characterized by inflammatory lesions of the white matter of the central nervous system, disseminated in time and space. The average onset age is 30 years. The infantile form is rare, in fact, the prevalence before the age of 17 varies from 0.4 to $5.6 \%$ while it occurs exceptionally before the age of 10 years [1].

The aim of this work is to report the clinical and radiological features of the childhood multiple sclerosis through a case report of a 13-year-old girl

\section{Case Report}

We report a case of a 13-year-old child with no particular medical history who presented symptoms of functional impotence of the lower limbs, balance disorders associated with rotational vertigo. Clinical examination found statokinetic cerebellar syndrome, central vestibular syndrome, and parapyramidal syndrome. An encephalic and medullary MRI showed the presence of several nodular lesions that are hypointense on $\mathrm{T} 1$ sequence and hyperintense on $\mathrm{T} 2$, of infra-centimeter size, which locates in periventricul arareas, semi circular centers, and involves supratentorial, infratentorial and medullar compartments (Fig-1 \& 2).

The other tests (blood tests, VEP) were in favor of a demyelinating condition.

The diagnosis of MS was based on a cluster of clinical, biological, electrophysiological and radiological arguments.

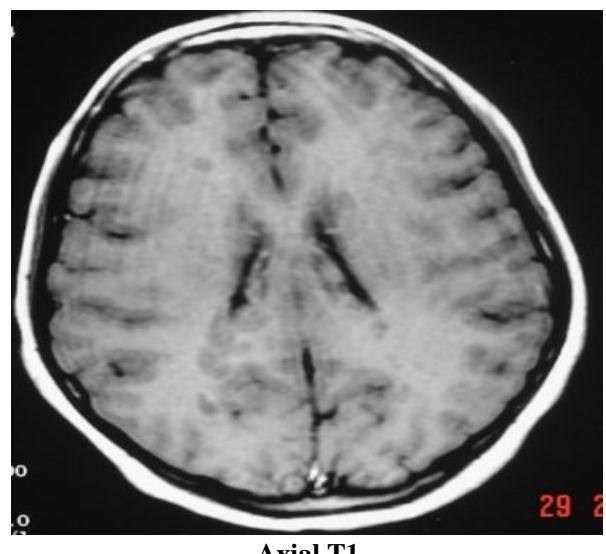

Axial T1 

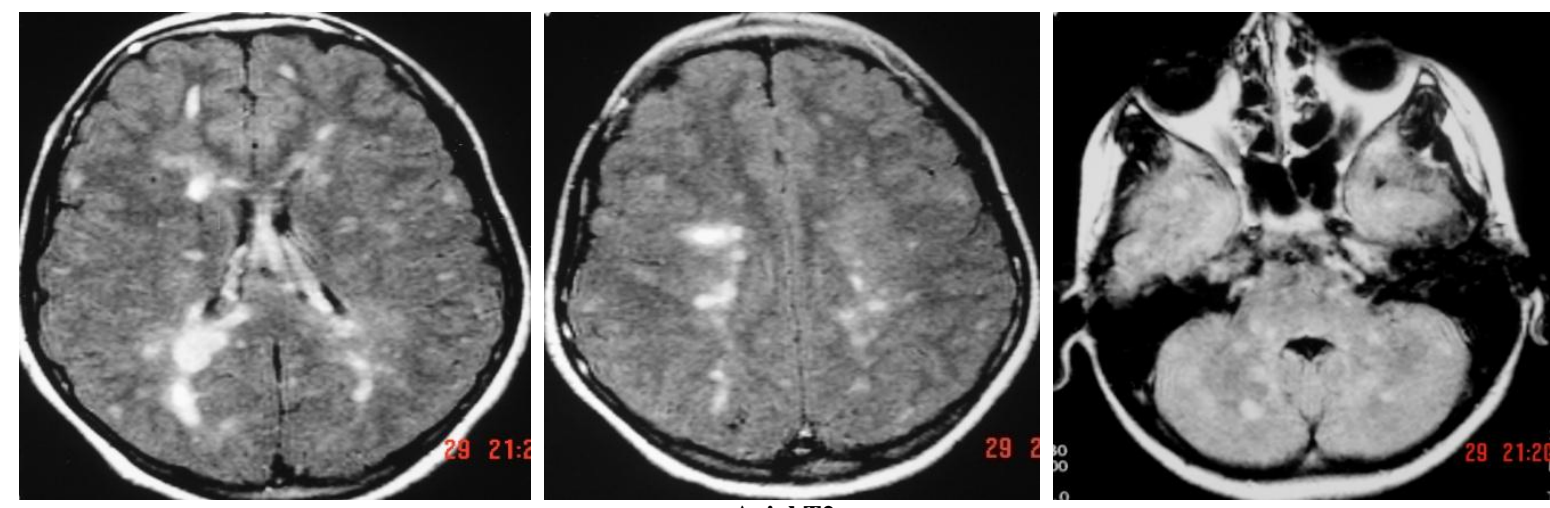

Axial T2

Fig-1: Brain MRI in axial T1 and T2 flair: demyelinating lesions hypointense in T1 and T2 sequences, located in periventricular compartment, at semi oval centers, trunk and cerebellar hemispheres

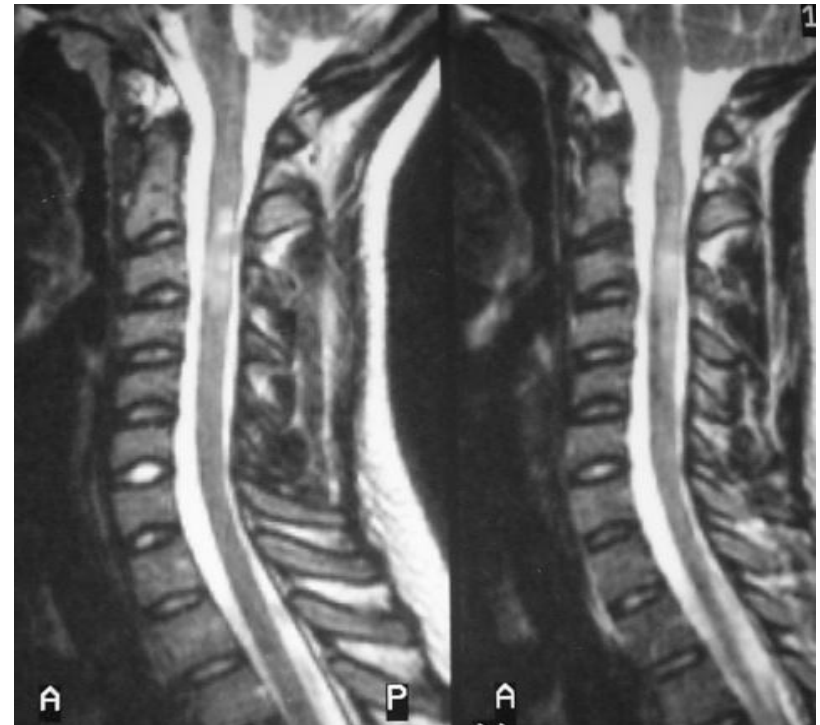

Fig-2: Medullary MRI in T2 sagittal section: Hyperintense T2 demyelinating plaques located on the cervical cord

\section{DISCUSSION}

Multiple sclerosis is a disease that usually occurs in adulthood. Infantile involvement is rare. Its occurrence before the age of 17 varies from 0.5 to $5.6 \%$ of cases, an onset before the age of 10 is exceptional [1].

The initial symptomatology is not different from that seen in adults, but it is usually mono symptomatic. Retrobulbar optic neuritis is the most common feature seen in 17 to $20 \%$ of cases [2]. Sensory manifestations are seen in $10 \%$ of cases, while the prevalence of motor manifestations varies from 26 to $55 \%$, the transverse myelitisis reported in 3 to $15 \%$ of the cases. Sometimes the onset is marked by an acute encephalopathy suggestive of viral encephalitis or tumor $[1,3]$.

The general outcome of childhood MS is comparable to that of adults. In pediatric population, the remittent form is the most common and the onset is usualy market by a relapse in 78 to $94 \%$ of cases [4].
MRI is sensitive in the detection of brain lesions of multiple sclerosis, its sensitivity varies from 80 to $95 \%$. The MRI semiology of multiple sclerosis is identical to that of the adult: homogeneous demyelination lesions in iso or hypointensity in $\mathrm{T} 1$ sequences, hyperintensity in $\mathrm{T} 2$ and $\mathrm{T} 2$ flair $[4,5]$. These lesions are generally multiple, bilateral, symmetrical and of different size (from $2 \mathrm{~mm}$ to 2.5 $\mathrm{mm}$ ). The shape of lesions is variable: rounded, polylobed, punctiform. They are sometimes confluent and do not cause mass effect on adjacent structures. The lesions predominate largely in the white matter, most often in the periventricular and semi oval centers. They also concern the brainstem, the cerebellar hemispheres in contact with the 4th ventricle. In addition to these demyelinating lesions, cerebrala trophy is observed in MS that has been evolving for a long time. It involves the corpus callosum and results in dilatation of the ventricles and subarachnoid spaces [1, 3-5].

Differential diagnoses is partly different from the adult: metabolic diseases and leukodystrophies [4]. A more difficult diagnosis is post-infectious disseminated encephalomyelitis [4, 5]. MRI allows differential diagnosis. In this case, it shows lesions of 
the sub-cortical white matter, sparing the periventricular regions, with an asymmetrical fronto-parietal predominance [5]. These lesions may be more typical, forming broad, confluent patches, involving the gray matter, basal ganglia, thalamus and brainstem with contrast enhancement of most lesions. However, in 50 to $70 \%$ of cases these lesions are not distinct from MS and the evolution remains the best diagnostic criterion [5].

\section{CONCLUSION}

Multiple sclerosis in children is rare. It presents similar clinical and evolutionary particularities as for adult form. MRI features are the same seen in adults and is still of major interest, especially for the differential diagnosis mainly with disseminated acute encephalomyelitis.

\section{REFERENCES}

1. Roullet E. La sclérose en plaques chez l'enfant. Revue neurologique (Paris). 1998;154(8-9):61922.

2. Roussat B, Gohier P, Doummar D, Iba-Zizen MT, Barbat V. Les neuropathies optiques aiguës de l'enfant: particularités cliniques et thérapeutiques. À propos de 28 yeux chez 20 enfants. Journal français d'ophtalmologie. 2001;24(1):36-44.

3. Sazdovitch V, Verdier-Taillefer MH, Heinzlef O, Alamowitch S, Roullet E. Sclérose en plaques familiale: étude de 357 patients consécutifs. Revue neurologique (Paris). 2000;156(6-7):638-40.

4. Dupel-Pottier C. Critères diagnostiques des formes frontières de sclérose en plaques. Revue neurologique (Paris). 2001;157(8-9):935-43.

5. Lebrun C, Ghetau G, Bourg V, Chanalet S, Chatel M. Sclérose en plaques rémittente ou encéphalomyélite multiphasique disséminée? Revue Neurologique. 2005 Feb 1;161(2):228-33. 